\title{
Veress needle insertion in the left hypochondrium in creation of the pneumoperitoneum ${ }^{1}$
}

\author{
Punção no hipocôndrio esquerdo com agulha de Veress para a criação do \\ pneumoperitônio
}

\author{
Otávio Cansanção deAzevedo ${ }^{2}$, João Luiz Moreira Coutinho Azevedo ${ }^{3}$, Albino Augusto Sorbello ${ }^{4}$, Gustavo Peixoto Soares \\ Miguel $^{5}$, Rodrigo Santa Cruz Guindalini ${ }^{6}$,Antônio Cláudio de Godoy ${ }^{7}$
}

1. Study performed at the Service of Surgical Gastroenterology, Public Servant Hospital of the State of São Paulo (HSPE) and the Service of Video Surgery, Division of Operative Technique and Experimental Surgery Federal University of São Paulo (UNIFESP), Brazil.

2. MD, Post-Graduate fellow. Post-Graduation Program in Surgery and Experimentation, UNIFESP, Brazil.

3. MD, Master, PhD, Associate Professor of Surgery, Chief of the Center of Minimally Invasive Surgery, Division of Experimental Surgery, Department of Surgery, UNIFESP, Brazil.

4. MD, PhD, Chief of Division of Laparoscopy Public Servant Hospital of the State of São Paulo (HSPE), Brazil.

5. MD, Master in Surgery, Post-Graduate fellow, Post-Graduation Program in Surgery and Experimentation, UNIFESP, Brazil.

6. Medical student of UNIFESP, Brazil.

7. Director, Service of Surgical Gastroenterology, Public Servant Hospital of the State of São Paulo (HSPE), Brazil.

\begin{abstract}
Purpose. To test the efficacy of the puncture in the left hypochondrium as an alternative method. Methods: Sixty-two patients randomly distributed into two groups were studied: Group LH, puncture in the left hypochondrium ( $\mathrm{n}=30$ ), and Group ML, puncture in the abdominal midline $(n=32)$. The following were assessed: needle positioning tests, number of failed attempts at needle insertion, and time needed for creation of pneumoperitoneum. Gas flow, volume and intraperitoneal pressure were recorded at every 20 seconds, until a $12 \mathrm{mmHg}$ pressure was reached inside the peritoneal cavity. Results: A similar number of positive results for the needle positioning tests were observed in both groups. Two failed attempts to reach the peritoneal cavity were observed in Group ML and one in Group LH. The time necessary for the creation of pneumoperitoneum was on average 3 minutes and 46 seconds for Group LH, and 4 minutes and 2 seconds for Group ML. Average gas flow, volume and pressure were equivalent for both groups. Conclusion: Puncture in the left hypochondrium was as effective as puncture in the abdominal midline for the creation of pneumoperitoneum.
\end{abstract}

Key words: Laparoscopy. Surgery. Pneumoperitoneum, Artificial. Punctures.

\section{RESUMO}

Objetivo: Avaliar a eficácia e segurança da punção alternativa no hipocôndrio esquerdo. Métodos: Sessenta e dois pacientes distribuídos aleatoriamente em dois grupos foram estudados prospectivamente: grupo HE, punção no hipocôndrio esquerdo $(n=30)$ e grupo LM, punção na linha média do abdome $(n=32)$. Foram avaliados os testes de posicionamento da agulha, o número de tentativas frustradas e a duração da instalação do pneumoperitônio. Os fluxos correntes, as pressões intraperitoneais e os volumes injetados foram registrados a cada 20 segundos, até $12 \mathrm{mmHg}$. Resultados: O número de resultados positivos aos testes de posicionamento da agulha foi semelhante em ambos os grupos. Ocorreram duas tentativas infrutíferas de punção no grupo LM e uma no grupo HE. O tempo necessário para o estabelecimento do pneumoperitônio foi, em média, 3 minutos e 46 segundos para o Grupo HE e 4 minutos e 2 segundos para o grupo LM. As médias dos fluxos, das pressões e dos volumes foram respectivamente equivalentes entre os grupos.. Conclusão: A punção no HE foi tão eficaz no estabelecimento do pneumoperitônio quanto a punção na LM do abdome.

Descritores: Laparoscopia. Cirurgia. Pneumoperitônio Artificial. Punções.

\section{Introduction}

The creation of a pneumoperitoneum is the first step of a laparoscopy. Most complications of laparoscopic surgery occur during its most critical step, namely access to the peritoneal cavity ${ }^{1}$. This is due to a significant risk of vascular and visceral injury ${ }^{2}$. Vascular injury is the most common cause of death during laparoscopic procedures $(15 \%)^{3}$. There may be damage to the great vessels when the
Veress needle is blindly inserted into the abdomen before insufflation, as it is done in the closed technique ${ }^{3}$. There is no consensus with regard to the best method of gaining access to the peritoneal cavity for the creation of the pneumoperitoneum ${ }^{4}$. The Veress needle technique is the most frequently used method ${ }^{5}$. A study that assessed 155,987 laparoscopic procedures showed that the Veress 
needle was used in $81 \%$ of them ${ }^{5}$. The Veress needle is typically inserted through the abdominal midline, at the umbilicus $^{6}$. In this region, there is risk of injury to the great vessels due to the close proximity of the anterior abdominal wall to the retroperitoneal vascular structures. In thin people, this distance can be as little as two centimeters ${ }^{3}$. The distal aorta and inferior vena cava, as well as the common iliac arteries are particularly prone to injury during the insertion of the Veress needle into the umbilical region. These injuries are severe complications that might result from blind insertion of the Veress needle to establish pneumoperitoneum: "Without a doubt, the most dramatic event a videosurgical team can experience is major vascular injuries. Even if the reported incidence is very low (0.05\%), the mortality arising from these lesions reportedly ranges between $8 \%$ and $17 \%{ }^{7}$. Albeit effective, insertion of the Veress needle through the midline poses danger. All injuries to the great vessels caused by the Veress needle reported in the literature resulted from midline punctures in the umbilical region ${ }^{2,3,5}$. The risk of iatrogenic injury is minimized when the needle is not inserted through the midline ${ }^{8-10}$. Patients with previous abdominal surgery are more prone to visceral injury caused by the Veress needle ${ }^{3}$. This is due to peritoneal adhesions, which typically grow where the incision of the parietal peritoneum was made ${ }^{11}$. Autopsy studies have found adhesions in $74 \%$ to $95 \%$ of patients with previous abdominal surgery ${ }^{3}$. Midline incisions greatly increase the risk of adhesions in the umbilical region. Even incisions made away from the umbilicus may lead to adhesion formation in the periumbilical region ${ }^{3}$. On the other hand, insertion of the Veress needle into the left hypochondrium has been reported as safe, with reduced risk of iatrogenic injury ${ }^{8-10}$. The stomach is immediately below the anterior abdominal wall at the site where the left hypochondrium puncture is made. If the stomach is accidentally perforated, its contents will not necessarily leak. This is due to the protection provided by the three layers of gastric muscle, which tend to close the puncture. A stomach perforation is easy to diagnose upon initial inspection of the peritoneal cavity, and can be repaired by laparoscopic suture. In addition, when the stomach is insufflated with gas, an accidental puncture can be easily detected, since a large amount of gas will escape through the orogastric tube. Adhesion formation in the left hypochondriac region is rare. Contraction and expansion of the diaphragm during breathing prevent peritoneal adhesions between intra-abdominal structures and the abdominal wall in the left hypochondriac region. Insertion of the Veress needle into the left hypochondrium is therefore the method of choice for some surgeons when operating on patients who are obese or have undergone laparotomy ${ }^{11,12}$. Although in theory Veress needle insertion into the left hypochondrium is safer than insertion into the midline, there are no comparative studies in the literature to corroborate that. If both techniques are equally effective, it is obvious that insertion into the left hypochondrium should be preferred because it is less dangerous. The purpose of this study was to analyze whether insertion of the Veress needle into the left hypochondrium to establish pneumoperitoneum is a safe and effective alternative to midline insertion into the periumbilical region.

\section{Methods}

This was a prospective, randomized clinical trial that tested the efficacy of the creation of pneumoperitoneum through insertion of a Veress needle into the left hypochondrium, as compared with insertion of a Veress needle into the abdominal midline. A total of sixty-two patients, adult and non-obese (body mass index lower than $30 \mathrm{Kg} / \mathrm{m}^{2}$ ), with no previous peritonitis or peritoneal cavity surgery, were scheduled to undergo laparoscopy at the Surgical Gastroenterology Service of The Civil Servant Hospital of the state of São Paulo (HSPE). Patients were randomly distributed into group $\mathrm{LH}(\mathrm{n}=30$, insertion of the Veress needle into the left hypochondrium) and group ML ( $n=32$, insertion of the Veress needle into the abdominal midline, in the umbilical region). Demographic data of the sample are showed in the Table 1.

This study was approved by the Research Ethics Committees of the Health Care Institute for the State Civil Servant (protocol n. 045/03), and of the Federal University of São Paulo (protocol n. 1405/03). Groups LH and ML were equivalent (Table) with regard to age, sex, body mass index (BMI), height, weight and clinical condition that required laparoscopy ( $\mathrm{p}<0.05)$. Randomization of patients was performed by the anesthesiologist (by flipping a coin) when patients were already anesthetized, immediately prior to the surgical procedure. A dosage of $0.1 \mathrm{mg} / \mathrm{Kg}$ of midazolam was administered to patients 30 minutes before anesthesia. For induction of anesthesia, doses of $2 \mathrm{mg} / \mathrm{Kg}$ of propofol and of $0.5 \mathrm{mcg} / \mathrm{Kg}$ of fentanyl were used. For curarization, a dosage of $0.5 \mathrm{mg} / \mathrm{kg}$ of atracurium was used. Patients were submitted to general anesthesia with orotracheal intubation and controlled mechanical ventilation. Then, an orogastric tube was inserted for aspiration of the stomach contents. For the midline puncture, a $12 \mathrm{~mm}$ longitudinal skin incision was made in the supraumbilical region with patients in the Trendelenburg position (approximately 20 degrees). Subcutaneous tissue divulsion with Kelly forceps followed, for visualization of the aponeurosis. Then, the aponeurosis was held and pulled with Kocher forceps to lift the abdominal wall. A Veress needle was obliquely inserted (20 degrees) into the abdominal cavity, through the midline, with a caudal orientation (Figure 1).

For the left hypochondrium puncture, a $1.2 \mathrm{~mm}$ skin incision was made in the costal margin, about $8 \mathrm{~cm}$ from the midline (Figure 2). A Veress needle was then inserted through this incision, perpendicularly to the anterior abdominal wall. Patients were positioned on a table, whose head was tilted upward approximately 20 degrees. In both groups, wellestablished tests were used to verify whether the needle was inside the peritoneal cavity: aspiration, injection, recovery and saline drop. In addition, initial pressure was measured before insufflations. Aspiration test was performed using a syringe attached to the Veress needle. This test was considered positive when no material was aspirated. Injection test was performed by injecting $5 \mathrm{ml}$ of saline through the needle. Resistance to liquid flow was observed; this test was considered positive in cases of no increased resistance to liquid flow. Recovery test consisted in trying to aspirate the saline solution injected. This test was considered positive in cases where no liquid was recovered. 
TABLE 1 - Demographic data of the sample and comparison between ML (midline puncture) and LH (left hypochondrium) groups

\begin{tabular}{|c|c|c|c|}
\hline \multirow[b]{2}{*}{ Parameters } & \multicolumn{2}{|c|}{ Technique } & \multirow[b]{2}{*}{ Comparisor } \\
\hline & $\mathrm{ML}(\mathrm{n}=32)$ & $\mathrm{LH}(\mathrm{n}=30)$ & \\
\hline $\begin{array}{l}\text { Age (years) } \\
\text { Mean (SD) } \\
\text { Minimum-maximum }\end{array}$ & $\begin{array}{l}53.2(12.8) \\
31-77\end{array}$ & $\begin{array}{l}54.3(13.6) \\
27-77\end{array}$ & $\mathrm{p}_{1}=0.748$ \\
\hline $\begin{array}{l}\text { Sex }-\mathrm{n}(\%) \\
\text { Female } \\
\text { Male }\end{array}$ & $\begin{array}{l}19(59.4) \\
13(40.6)\end{array}$ & $\begin{array}{l}17(56.7) \\
13(43.3)\end{array}$ & $\mathrm{p}_{2}=0.829$ \\
\hline $\begin{array}{l}\operatorname{BMI}\left(\mathrm{kg} / \mathrm{m}^{2}\right) \\
\text { Mean }(\mathrm{SD}) \\
\text { Minimum-maximum }\end{array}$ & $\begin{array}{l}25.4(2.4) \\
20.6-29.4\end{array}$ & $\begin{array}{l}25.4(2.5) \\
21.0-29.7\end{array}$ & $\mathrm{p}_{1}=0.969$ \\
\hline $\begin{array}{l}\text { Height (m) } \\
\text { Mean (SD) } \\
\text { Minimum-maximum }\end{array}$ & $\begin{array}{l}1.64(0.10) \\
1.45-1.87\end{array}$ & $\begin{array}{l}1.64(0.08) \\
1.48-1.78\end{array}$ & $\mathrm{p}_{1}=0.995$ \\
\hline $\begin{array}{l}\text { Weight (kg) } \\
\text { Mean (SD) } \\
\text { Minimum-maximum }\end{array}$ & $\begin{array}{l}68.8(11.0) \\
49.5-90.0\end{array}$ & $\begin{array}{l}68.7(8.7) \\
53.0-89.8\end{array}$ & $\mathrm{p}_{1}=0.957$ \\
\hline $\begin{array}{l}\text { Clinical condition }-\mathrm{n}(\%) \\
\text { Chronic cholecystopathy } \\
\text { Gastroesophageal reflux } \\
\text { Bilateral inguinal hernia } \\
\text { Right inguinal hernia } \\
\text { Left inguinal hernia }\end{array}$ & $\begin{array}{l}19(59.4) \\
5(15.6) \\
1(3.1) \\
3(9.4) \\
4(14.5)\end{array}$ & $\begin{array}{l}23(76.7) \\
4(13.3) \\
2(6.7) \\
0(0.0) \\
1(3.3)\end{array}$ & $\mathrm{p}_{2}=0.234$ \\
\hline
\end{tabular}

SD: standard deviation; n: number of patients; $\mathrm{p}_{1}$ : Student's t-test; $\mathrm{p}_{2}$ : Chi-squared test.

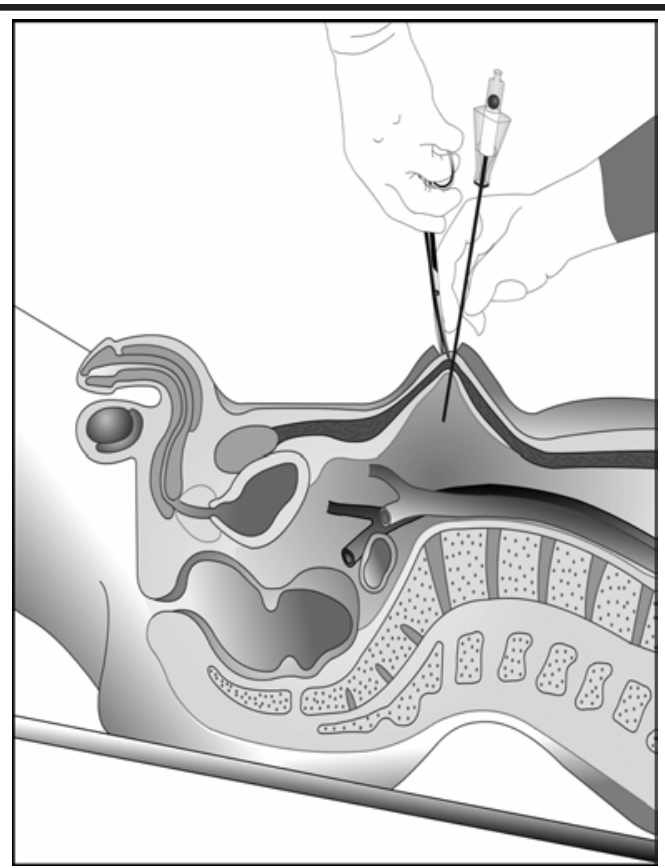

FIGURE 1 - Schematic illustration showing Veress needle puncture in the abdominal midline, at the umbilicus. Sagittal view of the abdominal and pelvic regions showing the skin and subcutaneous incision, through which a forceps was introduced for traction of the anterior aponeurosis of the rectus muscle and insertion of the Veress needle into the abdominal cavity. Note the proximity to the great vessels

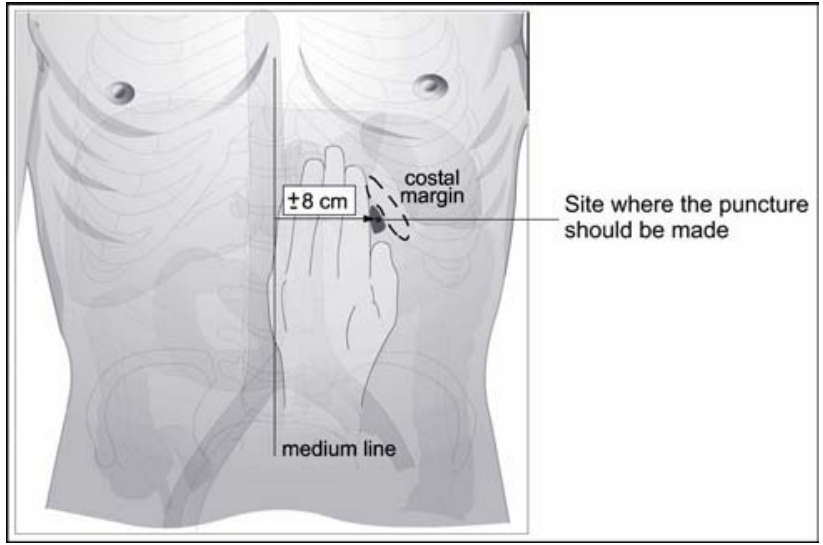

FIGURE 2 - Schematic illustration showing Veress needle puncture in the left hypochondriac region, at the costal margin, $8 \mathrm{~cm}$ from the midline. Note the entry point of the needle and the distance from the great vessels 
Saline drop test consisted in pouring $2 \mathrm{ml}$ of saline into the needle. This test was considered positive if the liquid disappeared after removing the syringe. When any of the tests above were considered negative, the procedure was aborted. Failed attempts to reach the peritoneal cavity were recorded and the entire procedure started again.

The peritoneal cavity was only insufflated with carbonic gas when all of the four previous tests were considered positive. Final intraperitoneal pressure was set at $12 \mathrm{mmHg}$ and maximum flow rate at one liter per minute. In case initial intraperitoneal pressure was over $8 \mathrm{mmHg}$ during the first ten seconds of insufflation, initial pressure test was considered negative; the procedure was aborted, and the failed attempt was again recorded.

In case all tests were positive, insufflation continued. Variations in intraperitoneal pressure, gas flow rate and volume were recorded at every 20 seconds, until intraperitoneal pressure reached $12 \mathrm{mmHg}$. The total time necessary for insufflation was also recorded.

The data were submitted to statistical analysis. Qualitative variables were represented by absolute and relative frequencies. Quantitative variables were represented by mean, standard deviation, and minimum and maximum values. Homogeneity between groups was assessed by means of the Student's $t$-test or chi-squared test, when necessary. Significance level was set at $0.05(\mathrm{a}=5 \%)$. Equivalence between groups with regard to intraoperative and postoperative parameters was determined by overlapping confidence intervals $\left(\mathrm{CI}_{95 \%}\right)$ constructed for each parameter assessed within each group. Intervals with 95\% confidence level for means and proportions were constructed assuming normal distribution. To assess distribution of pressure, volume and flow in function of time, polynomial regression models (first, second and third order) were estimated, and adjustment was based on analysis of residuals and coefficient of determination $\left(\mathrm{R}^{2}\right)$. Intervals with confidence level of 95\% were constructed for each coefficient estimated by the model, and both groups were compared according to these intervals.

\section{Results}

When the Veress needle was not inserted into the peritoneal cavity, as detected by each of the tests performed, confidence intervals for both groups overlapped. Thus, both groups were statistically equivalent with regard to the proportion of failed attempts to reach the peritoneal cavity (Figure 3 ).

With regard to the average time necessary for the creation of pneumoperitoneum (final pressure of $12 \mathrm{mmHg}$ ), no significant statistical difference was found between the groups, as determined by the overlapping confidence intervals (Figure 4).

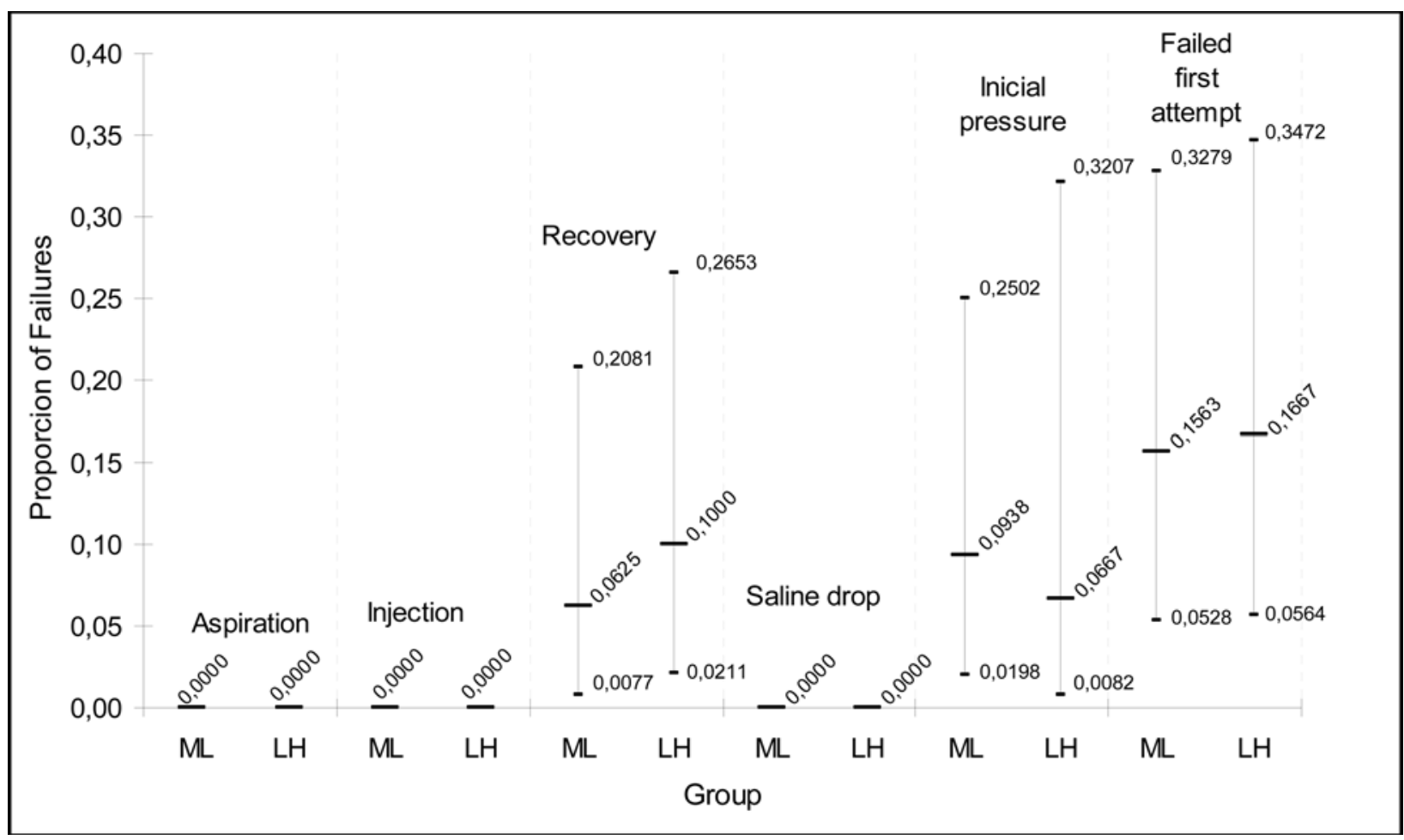

FIGURE 3 - Proportion and respective 95\% confidence intervals of failed attempts to reach the peritoneal cavity, according to the different tests carried out in Groups ML (midline puncture) and LH (left hypochondrium puncture). Notice that, for each test, the confidence intervals constructed for both groups overlapped. Thus, both groups are statistically equivalent with regard to the proportion of failures 


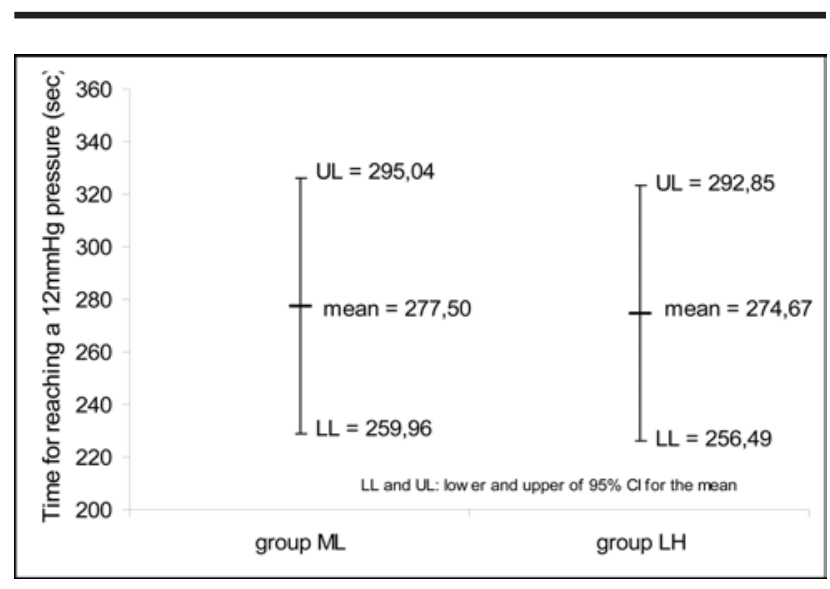

FIGURE 4 - Means, upper limit (UL) and lower limit (LL) of $95 \%$ confidence intervals for the time necessary to reach a $12 \mathrm{mmHg}$ pressure in Groups ML (midline puncture) and LH (left hypochondrium puncture). No significant difference between means for both groups was observed, as determined by the overlapping confidence intervals.

No significant statistical difference was found between both groups when comparing the regression curves of the dependent variables: intraperitoneal pressure (Figure 5), gas flow (Figure 6) and volume (Figure 7); as determined by the overlapping confidence intervals and estimated model coefficients for each group. No significant statistical difference was found between the mean areas under the curves for intraperitoneal pressure (Figure 8), gas flow (Figure 9) and volume (Figure 10).

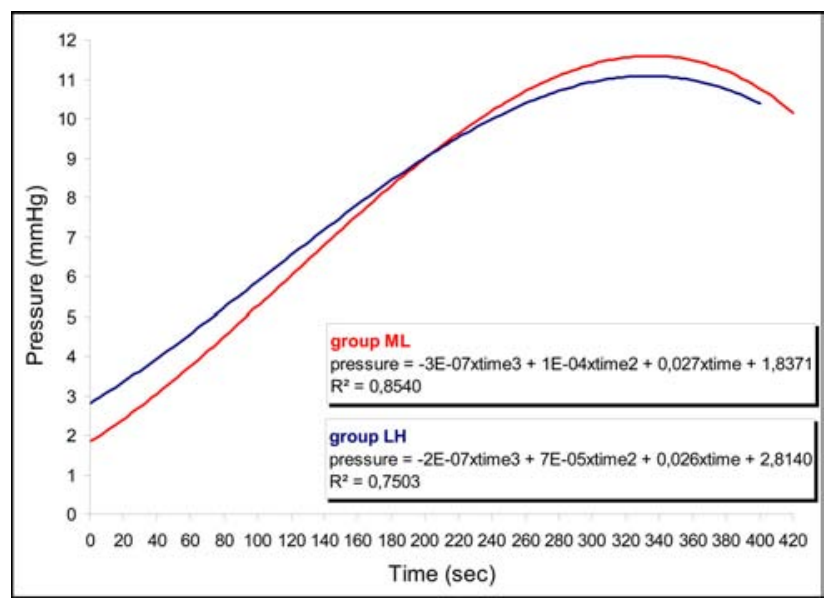

FIGURE 5 - Estimated pressure curves in function of time for Group ML (midline puncture) and Group LH (left hypochondrium puncture). Coefficients of determination (R2) were high and statistically similar

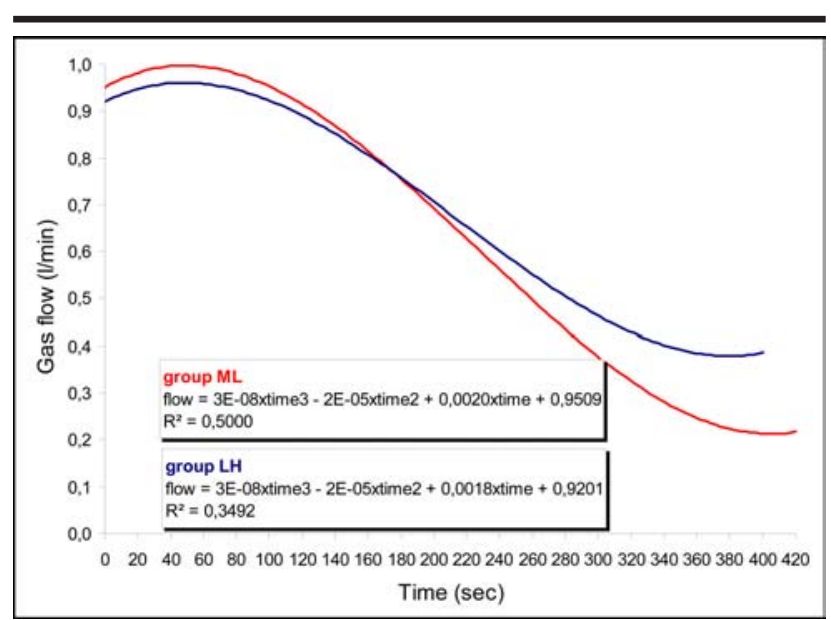

FIGURE 6 - Estimated gas flow curves in function of time for Group ML (midline puncture) and Group $\mathrm{LH}$ (left hypochondrium puncture). Coefficients of determination (R2) were low and statistically similar

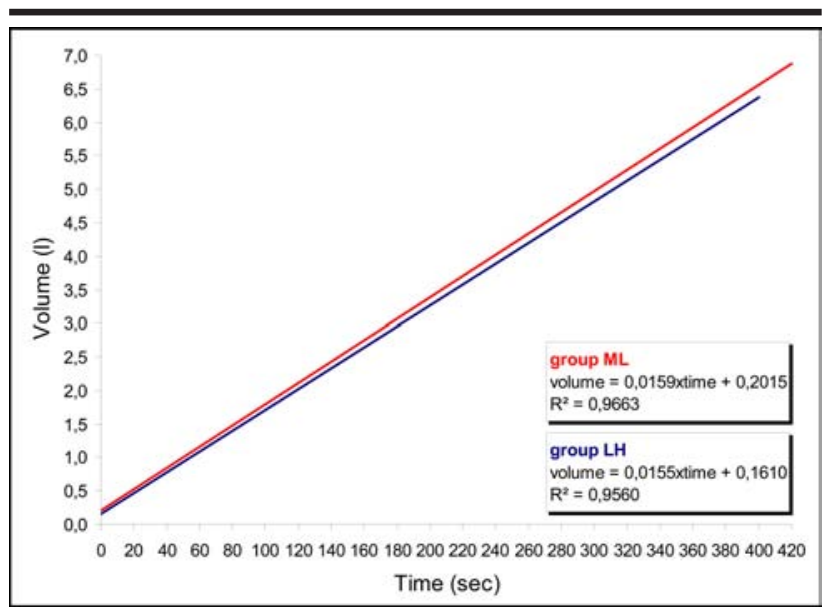

FIGURE 7 - Estimated volume curves in function of time for Group ML (midline puncture) and Group LH (left hypochondrium puncture). Coefficients of determination (R2) were very high and statistically similar

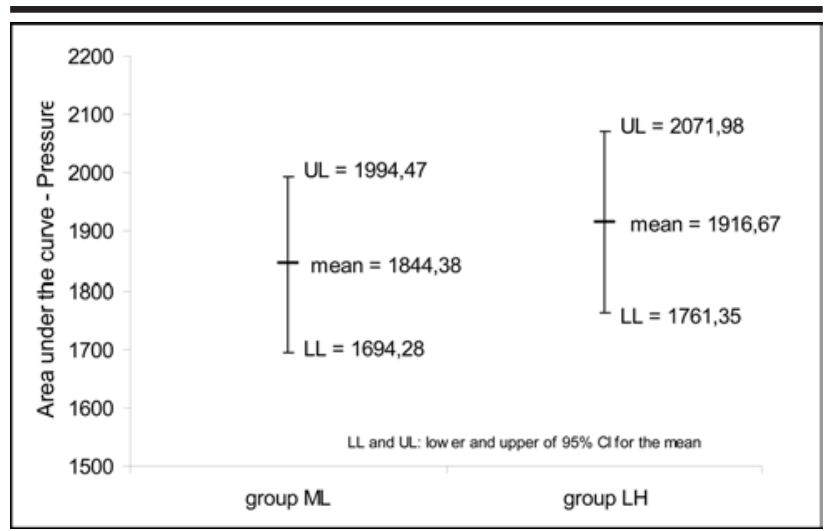

FIGURE 8 - Means, upper limit (UL) and lower limit (LL) of confidence intervals (CI95\%) for the areas under the curves for pressure, for Group ML (midline puncture) and Group LH (left hypochondrium puncture). No statistically significant difference was found between the means, as determined by the overlapping confidence intervals 


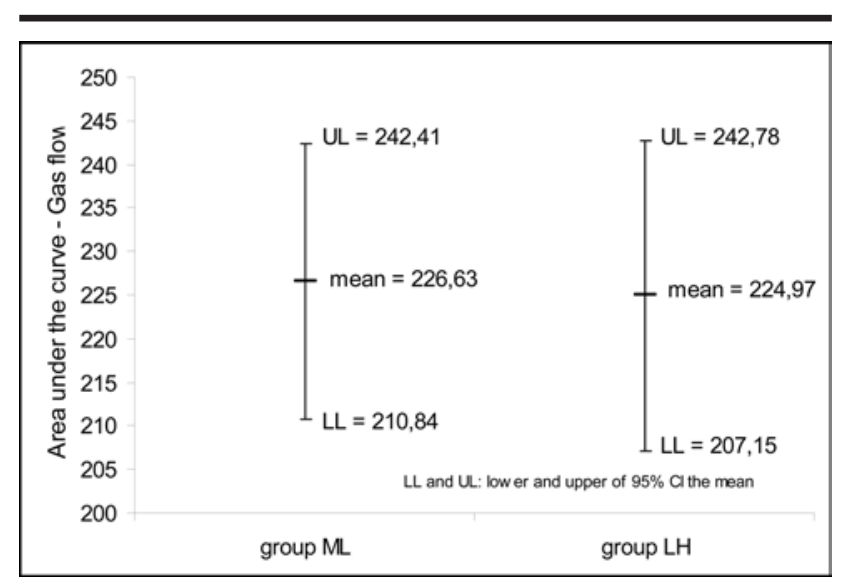

FIGURE 9 - Means, upper limit (UL) and lower limit (LL) of confidence intervals (CI95\%) for the areas under the curves for gas flow, for Group ML (midline puncture) and Group LH (left hypochondrium puncture). No statistically significant difference was found between the means, as determined by the overlapping confidence intervals

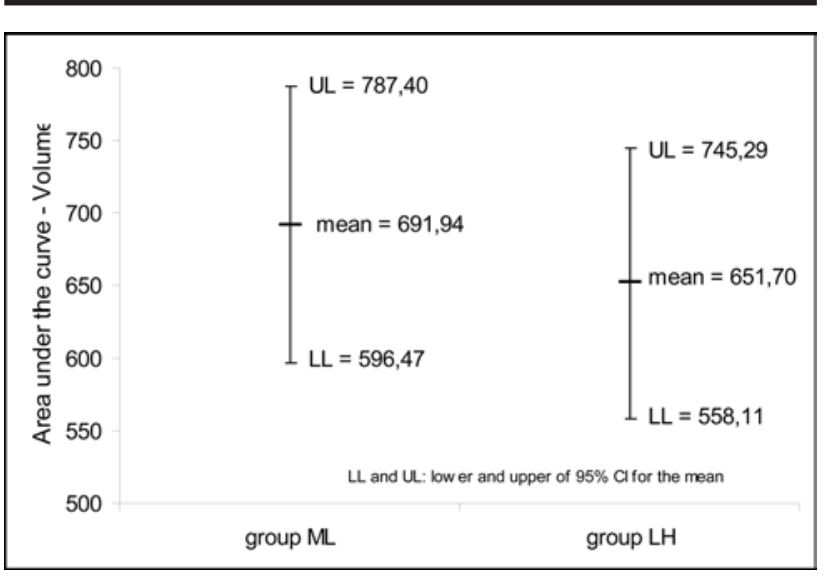

FIGURE 10 - Means, upper limit (UL) and lower limit (LL) of confidence intervals (CI95\%) for the areas under the curves for volume, for Group ML (midline puncture) and Group LH (left hypochondrium puncture). No statistically significant difference was found between the means, as determined by the overlapping confidence intervals

\section{Discussion}

Over the last two decades, rapid advances have made laparoscopic surgery a well-established procedure. However, because laparoscopy is relatively new, it still arouses controversy, particularly with regard to the best method for the creation of the pneumoperitoneum.

To establish the pneumoperitoneum, access to the peritoneal cavity can be gained through minilaparotomy and insertion of a laparoscopic trocar ${ }^{13}$ or Hasson trocar ${ }^{14}$. Alternatively, an optical trocar can be blindly inserted into the peritoneal cavity ${ }^{15}$, or a Veress needle may be inserted through the abdominal midline ${ }^{6}$. The latter is the most frequently used technique ${ }^{2,5}$.
Creation of pneumoperitoneum by insertion of a Veress needle is an easy, quick and effective technique. The first trocar can be subsequently introduced. This is particularly important in obese patients, because it minimizes the escape of gas during surgical intervention, makes the procedure easier to perform and saves time. The disadvantage of the Veress needle technique is the risk it poses. Injury to the great vessels caused by the needle is the most common cause of death during laparoscopy ${ }^{7}$. The most common entry points of the Veress needle are the umbilical region - considered the standard entry point ${ }^{6}$ - the left subcostal margin ${ }^{8-10}$, an intermediate point between the upper edge of the pubic symphysis and the umbilicus ${ }^{16}$ and a point identical to McBurney's, in the left iliac fossa ${ }^{6}$. There are also reports of gaining access to the peritoneal cavity through transfixion of the fundus of uterus with a needle introduced into the cervical canal of uterus ${ }^{17}$, and transfixion of the thoracoabdominal wall through the left ninth intercostal space ${ }^{10}$.

Studies have frequently investigated the issue of safety when the Veress needle is blindly inserted into the peritoneal cavity through the midline. Ostrzenski ${ }^{18}$ conducted a prospective, randomized, blinded study with 200 patients comparing the traditional midline puncture ${ }^{6}$ and a technique in which the Veress needle was caudally inserted into the periumbilical region forming a very sharp angle with the anterior abdominal wall, almost parallel to it. The study did not report any differences between the results obtained with one technique or another, and highlighted the advantages of an alternative puncture to prevent injury to the great vessels.

In a randomized study of patients with BMI $>25 \mathrm{Kg} /$ $\mathrm{m}^{2}$, Santala et al. ${ }^{17}$ compared the traditional method ${ }^{6}$ and a technique in which the Veress needle was introduced into the peritoneal cavity through the fundus of uterus. This technique proved effective, with no increase in the risk of bleeding, infection or injury to the pelvic organs. However, the technique is contraindicated in patients with a history of inflammatory pelvic disease, infertility, and patients prone to infraumbilical adhesions. The method increases the theoretical risk of endometriosis and adenomyosis, and it can only be performed in female patients. In addition, creation of pneumoperitoneum by causing injury to an organ does not appeal to surgeons. Palmer $^{8}$ described the insertion of the Veress needle through the left hypochondrium $3 \mathrm{~cm}$ below the costal margin, in the midclavicular line. The technique has since been slightly altered in order to avoid midline adhesions and injury to the great vessels. In the present study, the needle was inserted at the costal margin, $8 \mathrm{~cm}$ from the midline, avoiding the aorta, vena cava and superior epigastric vessels. In this region, the puncture is easier because the peritoneum is attached to the costal margin. Schwartz et al. ${ }^{12}$ established pneumoperitoneum in 600 patients with morbid obesity by inserting the Veress needle into the left hypochondrium. The muscular layer of the transverse colon was inadvertently punctured in one patient. The perforation was repaired by laparoscopic suture. No other hollow viscera were perforated. There was no abnormal bleeding of the abdominal wall or 
viscera, nor liver or spleen injury. Rothagi et al. ${ }^{9}$ performed 344 punctures in the left hypochondrium. Only two punctures failed to reach the peritoneal cavity. The only complication was bleeding of the greater omentum, for which expectant treatment was administered. The authors concluded that puncture of the left hypochondrium is an effective method for establishing pneumoperitoneum.

Some surgeons argue that it is more difficult to insert the needle through the left hypochondrium, and that more than one attempt might be necessary. Our study showed that both methods are statistically equivalent with regard to the proportion of failed and successful attempts to establish pneumoperitoneum. Both groups (ML and LH) were statistically equivalent with regard to the number of attempts and positive results to the needle positioning tests. This suggested that both methods present similar technical difficulties.

It was not known whether the time necessary for establishing pneumoperitoneum would be similar in both groups, and whether variations in pressure, gas flow and volume would be similar as well. In theory, there could be discrepancies due to the different topography of the abdomen at both entry points. The results of this study, however, indicated that both methods were statistically equivalent with regard to variations in these parameters.

With regard to theoretical discussions about possible iatrogenic injuries caused by insertion of the Veress needle through the left hypochondrium, no conclusive results were yielded by this study. These injuries are very rare in the hands of experienced surgeons. The great vessels do not lie in the hypochondrium, so injury to them is unlikely to be caused by punctures in this region. The colons and the small intestine do not lie beneath the site where the puncture is made. Similarly, a normal-sized spleen or liver does not lie beneath the left costal margin. On the other hand, both the stomach and the omenta are subjacent to the puncture site and might be inadvertently injured; such lesions, however, are not considered major injuries.

Adhesions in the left hypochondrium are very rare, as opposed to adhesions in the umbilical region. However, they may be observed in patients with previous splenectomy or colectomy who needed mobilization of the splenic flexure of colon. Puncture in the left hypochondrium should not be made in these patients.

Audebert and Gomel ${ }^{19}$ carried out a prospective study with 814 patients to estimate the frequency of peritoneal and visceral adhesions to the umbilical region according to previous surgeries. The insertion of a $1.2 \mathrm{~mm}$ laparoscope into the left hypochondrium showed the presence of peritoneal adhesions in the umbilical region. This eliminated the risk of bowel injuries caused by inadvertent insertion of the trocar in the umbilical region. The patients were divided into groups. The incidence of adhesions and risk determination were $0.68 \%$ and $42 \%$ among 469 patients with no history of previous surgeries, $1.6 \%$ and $0.8 \%$ among 125 patients with previous laparoscopy, $19.8 \%$ and $6.8 \%$ among 131 patients who had undergone laparoscopy with suprapubic insertion, and $51.7 \%$ and $31.4 \%$ among 89 patients who had undergone laparoscopy with midline insertion. Levrant et al. ${ }^{11}$ also observed that laparoscopy with midline insertion of the Veress needle increases the risk of adhesions to the anterior abdominal wall when compared with laparoscopy with transverse abdominal incision. Therefore, insertion of the Veress needle into the left hypochondrium for creation of pneumoperitoneum is safe and effective, and should be the chosen alternative.

\section{Conclusion}

Puncture in the left hypochondrium was as effective as puncture in the abdominal midline for the creation of pneumoperitoneum.

\section{References}

1. Bermelman WA, Dunker MS, Busch ORC, Boer KTD, Wit LTH, GoumaDJ. Efficacy of establishment of pneumoperitoneum with the Veress needle, Hasson trocar, and modified blunt trocar (TrocDoc): a randomized study. J Lapend Adv Surg Tech. 2000;10:325-30.

2. Catarci M, Carlini M, Gentileschi P, Santoro E. Major and minor injuries during the creation of pneumoperitoneum. Surg Endosc. 2001;15:566-9.

3. Anaise.D. Vascular and bowel injuries during laparoscopy. Available from URL: http://www.danaise.com/ vascular_and_bowel_injuries_duri.htm

4. Neudecker J, Sauerland S, Neugebauer E, Bergamaschi R, Bonjer H, Cuschieri A. The European Association for Endoscopic Surgery clinical practice guideline on the pneumoperitoneum for laparoscopic surgery. Surg Endosc. 2002;16:1121-43.

5. Molloy D, Kaloo PD, Cooper M, Nguyen TV. Laparoscopic entry: a literature review and analysis of techniques and complications of primary port entry. Aust N Z J Obstet Gynaecol. 2002;42:246-53.

6. Holthausen UH, Nagelschimidt M, Troidl H. $\mathrm{CO}_{2}$ pneumoperitoneum: what we know and what we need to know. World J Surg. 1999;23:794-800.

7. Roviaro GC, Varoli F, Saguatti L, Vergani C, Maciocco M, Scarduelli A. Major vascular injuries in laparoscopic surgery. Surg Endosc. 2002;16:1192-6.

8. Palmer R. Safety in laparoscopy. J Reprod Med. 1974;13:1-5.

9. Rohatgi A, Widdison AL. Left subcostal closed (Veress needle) approach is a safe method for creating a pneumoperitoneum. J Laparoendosc Adv Surg Tech. 2004;14:278-80.

10. Childers JM, Brzechffa PR, Surwit EA. Laparoscopy using the left upper quadrant as the primary trocar site. Gynecol Oncol. 1993;59:221-7.

11. Levrant SG, Bieber E, Barnes R. Risk of anterior abdominal wall adhesions Increase whith number and type of previous laparotomy. J Am Assoc Gynecol Laparosc. 1994;1(4 Part 2):S19. 
12. Schwartz ML, Drew RL, Andersen JN. Induction of pneumoperitoneum in morbidly obese patients. Obes Surg. 2003;13:601-4.

13. Dingfelder JR. Direct laparoscope trocar insertion without prior pneumoperitoneum. J Reprod Med. 1978;21:45-7.

14. Hasson H.M. A modifield instrument and method for laparoscopy. Am J Obstet Gynecol. 1971;13:886-7.

15. String A, Berbre E, Foroutani A, Macho JR, Pearl JM, Sperstein AE. Use of optical access trocar for safe and rapid entry in various laparoscopic procedures. Surg Endosc. 2001;15:570-3.
16. Lee C, Huang K, Jain S, Wang C, Yen C, Soong Y. A new portal for gynecologic laparoscopy. J Am Assoc Gynecol Laparosc. 2001;8:147-50.

17. Santala M, Jarvela I, Kauppila A. Tranfundal insertion of a Veress needle in laparoscopy of obese subjects:a pratical alternative. Hum Reprod. 1999;14:2277-8.

18. Ostrzenski A. Randomized, prospective, singleblind trial of a new parallel technique of Veress pneumoperitoneum needle insertion versus the conventional closed method. Fertil Steril. 1999;71:578-81.

19. Audebert AJ, Gomel V. Role of microlaparoscopy in the diagnosis of peritoneal and visceral adhesions and in the prevention of bowel injury associated whith blind trocar insertion. Fertil Steril. 2000;72:631-5.

\section{Correspondence:}

Prof Dr João Luiz M. C. Azevedo

Rua Botucatu, 740

04023-900 São Paulo - SP Brazil

Phone: (55 11)5576-4272

jozevedo.dcir@epm.br
Conflict of interest: none Financial source: none

Received: April 05, 2006

Review: May 11, 2006

Accepted: June 15, 2006

\title{
How to cite this article:
}

Azevedo OC, Azevedo JLMC, Sorbello AA, Miguel GPS, Guindalini RSC, Godoy AC. Veress needle insertion in the left hypochondrium in creation of the pneumoperitoneum. Acta Cir Bras. [serial on the Internet] 2006 Sept-Oct;21(5). Available from URL: http://www.scielo.br/acb.

\section{CONGRESSO NACIONAL SOBRADPEC}

\author{
Cuiabá - Mato Grosso
}

27 a 30 de Abril de 2007

Cirurgia 2007

Congresso Brasileiro de Cirurgia Geral

"Pesquisa e Inovação em Cirurgia"

Mais informações:

Prof. José Eduardo Aguilar Nascimento

Presidente da Regional Centro Oeste

e-mails.: aguilar@terra.com.br / aguilar@cpd.ufmt.br

www.sobradpec.org.br 